\title{
Ecopharmacovigillance aspect of unwanted and expired medications in Sulaimani, Kurdistan Region, Iraq
}

\begin{abstract}
Background and objective: Unwanted and expired medications are accumulated at the homes and the community Pharmacies due to many reasons. Improper disposal and its hazardous impact on the environment is one of the major issues. This study aimed to identify the currently followed methods of disposing expired/unused medications at the homes and the community pharmacies and to report the response of the pharmacists regarding disposal of medications in Sulaimani city.

Methods: This study was carried out between July 2015 and February 2016. A total of 145 houses and 62 pharmacies were observed utilizing a self-administered questionnaire. All expired/unwanted drugs were quantitatively analyzed.

Results: The results revealed that $95.2 \%$ of respondents throw away their unwanted pharmaceuticals in the garbage. Around $41 \%$ of respondents showed their awareness of the potential harm to the environment by improper disposal of medication while $59.3 \%$ were unaware. Most participants $(91 \%)$ believed that returning expired/unused medications to a community pharmacy is a proper way for disposal of them. Around $39 \%$ of the community pharmacies throw away the expired medications in the garbage, while $46.8 \%$ of them returned them to the suppliers. Additionally, $58.1 \%$ of the community pharmacists agreed to use their workplace as a collection point for collecting expired/unused medications.
\end{abstract}

Conclusion: High amount of expired/unused medications were kept in the households that necessitate establishing a procedure for disposal that ensures safety to human and environment. There was good interest in the collection of unused medications for proper disposal in the community pharmacies.

Keywords: Medication disposal; Expired medication; Community pharmacy; Safety.

\section{Introduction}

Unwanted medications include expired, unused, spilt and contaminated pharmaceutical products, drugs, vaccines and sera that are no longer required and need to be disposed of appropriately. The World Health Organization (WHO) recommends that unwanted medications should never be used and should always be considered as pharmaceutical wastes. ${ }^{1}$ The main source for piling up these unwanted or expired medications at home are over the counter (OTC) medicines bought for a previous illness and stored at home for future use. Those medicines may accumulate due to many reasons including medication misuse, poor medication adherence, and changes in therapy, complex medication regimens, polypharmacy and patient death. ${ }^{2,3}$ Disposal of unwanted medications at home by rinsing them down a sink, flushing them down a toilet, or throwing them in the garbage are commonly followed approaches. $^{4,5}$ Generally, pharmaceutical wastes that are disposed in the garbage or, rinse in the sink or flushed down the toilet, ends up in the water system and have a potential risk on the ecosystem as they could reach the underground water. $^{6}$

* Department of Pharmacology and Toxicology, School of Pharmacy, Faculty of Medical Sciences, University of Sulaimani, Sulaimani, Iraq. 
Active pharmaceutical ingredients are environmental contaminants and can find their way into drinking water sources through human excretion and improper drug disposal. ${ }^{7}$ According to the Food and Drug Administration (FDA), few drugs should be flushed down the toilet because they can pollute the water supply, and some medicines are extremely hazardous. Unfortunately, current water treatment systems do not remove many pharmaceuticals from drinking water., Moreover, hospitals and other healthcare establishments also generate wastes, of which chemicals and pharmaceuticals account for about 3\% of the total healthcare waste. ${ }^{10}$ Many pharmacists are unaware of the proper way to dispose waste medication in their pharmacies, and indeed they ad-vised patients to undertake their own disposal in a manner that was, unintentionally, environmen-tally unsafe. ${ }^{11}$ Currently few literature describe the methods and protocols used by pharmacies to dispose of unused medications. Awareness towards improper disposal of medicines (pharmaceuticals) and its hazardous impact on the environment is one of the major issues which is neglecting but needs to be focused. ${ }^{6}$ Pharmacovigilance became well accepted and practiced in the developed world. However and despite this achievement worldwide, the effect of drug use on the environment remains unaddressed..$^{12}$ Ecopharmacovigilance can be defined as a science and activities concerning detection, assessment, understanding, and prevention of adverse effects or other problems related to the presence of pharmaceuticals in the environment, which affect human and other animal species. ${ }^{13}$ Additionally, numerous medications have been found in trace amounts in groundwater, surface bodies of water, and in recent years, the existence of pharmaceuticals and their metabolites in water has been recognized as potentially dangerous. Continuous exposure to low dose of antimicrobials through drinking water may bring resistance. ${ }^{14}$ Standard protocols for drug disposal in many countries have not yet been established. Although one of the recommended methods for household expired drug disposal in many countries is to return them to community pharmacies, currently, little data exists on how unused medications are disposed of after they have been returned to pharmacies. ${ }^{15}$ The present study reports the response of the community pharmacists regarding disposal of medications, and identify the currently followed methods of disposing expired/ unused medications at homes and community pharmacies in Sulaimani city.

\section{Methods}

This cross-sectional study was carried out in Sulaimani city, Kurdistan region-Iraq from July 2015 to February 2016. The Ethical Committee at Sulaimani University, Faculty of Medical Sciences has approved the study. The study conducted in two parts; the first part aimed to identify the methods of disposing of expired/unused medications at homes utilizing one-page self-administered questionnaire as the instrument to gather information on disposal practices for unused and unwanted medications. One hundred and forty five houses were randomly selected from different geographical locations in Sulaimani city. The demographical data for the respondents were recorded in a suitable designed form including age, sex, educational level, and the currently followed procedure of disposal. All expired and unwanted drugs were collected from each house after the interview; the returned drugs were counted and categorized according to British National Formulary (BNF). In the second part, another questionnaire, specially formulated for the community pharmacists to record the methods currently followed in disposing expired or unused medications in their workplaces. The outcome of the questions expected to show whether the community pharmacists are ready to consider their 
workplace as a spot for gathering expired/ unused medications from the community. Descriptive statistics were used to analyze the results by using SPSS (version 23).

\section{Results}

A total of 145 houses and 64 community pharmacies were surveyed during the study period. Two pharmacists were refused to participate in the study. Among the 145 respondents from all the houses; $38(26.2 \%)$ were male and 107 (73.8\%) were female. The mean age of the respondents was $33.4 \pm 12.3$ and their education levels varied from illiterate (24.1\%), primary school $(7.6 \%)$, secondary school $(11.7 \%)$, institute graduate $(23.4 \%)$ and university graduate (33.1\%). Among the 62 respondent pharmacists, $52(83.9 \%)$ have ten or less than ten years of experience, $3(4.8 \%)$ have 11 to 20 years and $7(11.3 \%)$ have 21 to 30 years of experience as shown in Table 1.

Table 1: Demographic data of the participants.

\begin{tabular}{|c|c|c|c|}
\hline Variable and Categories & $\begin{array}{l}\text { Number of } \\
\text { responses }\end{array}$ & $\%$ & Mean $\pm S D$ \\
\hline \multicolumn{4}{|l|}{ Public Setting $n=145$} \\
\hline Respondents' age (years) & & & $33.4 \pm 12.3$ \\
\hline \multicolumn{4}{|l|}{ Education Level } \\
\hline Illiterate & 35 & 24.1 & \\
\hline Primary School & 11 & 7.6 & \\
\hline Secondary School & 17 & 11.7 & \\
\hline Institute Graduate & 34 & 23.4 & \\
\hline University Graduate & 48 & 33.1 & \\
\hline \multicolumn{4}{|l|}{ Gender } \\
\hline Male & 38 & 26.2 & \\
\hline Female & 107 & 73.8 & \\
\hline \multicolumn{4}{|c|}{ Community Pharmacy Setting $n=62$} \\
\hline \multicolumn{4}{|l|}{ Gender } \\
\hline Male & 37 & 59.7 & \\
\hline Female & 25 & 40.3 & \\
\hline \multicolumn{4}{|c|}{ Years of experience as a pharmacist } \\
\hline$£ 10$ & 52 & 83.9 & \\
\hline $11-20$ & 3 & 4.8 & \\
\hline $21-30$ & 7 & 11.3 & \\
\hline
\end{tabular}


Regarding the practice of expired instructions of the disposal, as mentioned medication disposal, the results of the current study revealed that the common way of getting rid of unwanted pharmaceuticals in the homes was throwing them away in the garbage $(95.2 \%) \quad$ (Figure 1) without following by the FDA. The respondents who showed their awareness about improper disposal of medications to environment represent $40.7 \%$ versus those who were unaware $(59.3 \%)$ as shown in Figure 2.

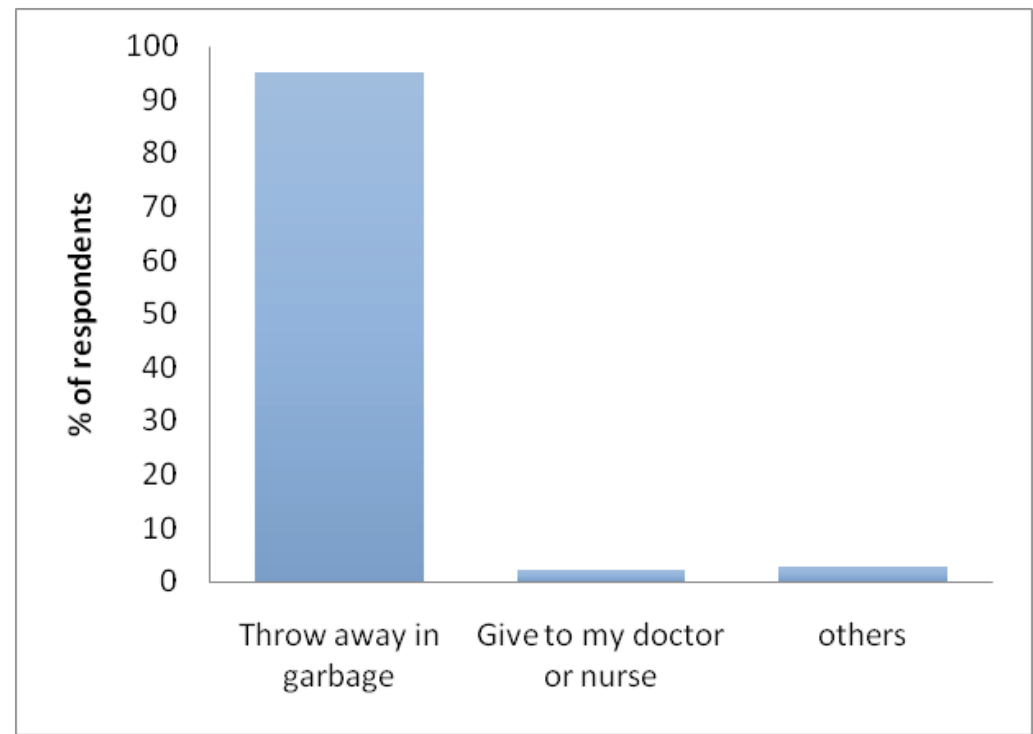

Figure 1: Disposal methods of expired/unused medications by the housekeepers in Sulaimani city.

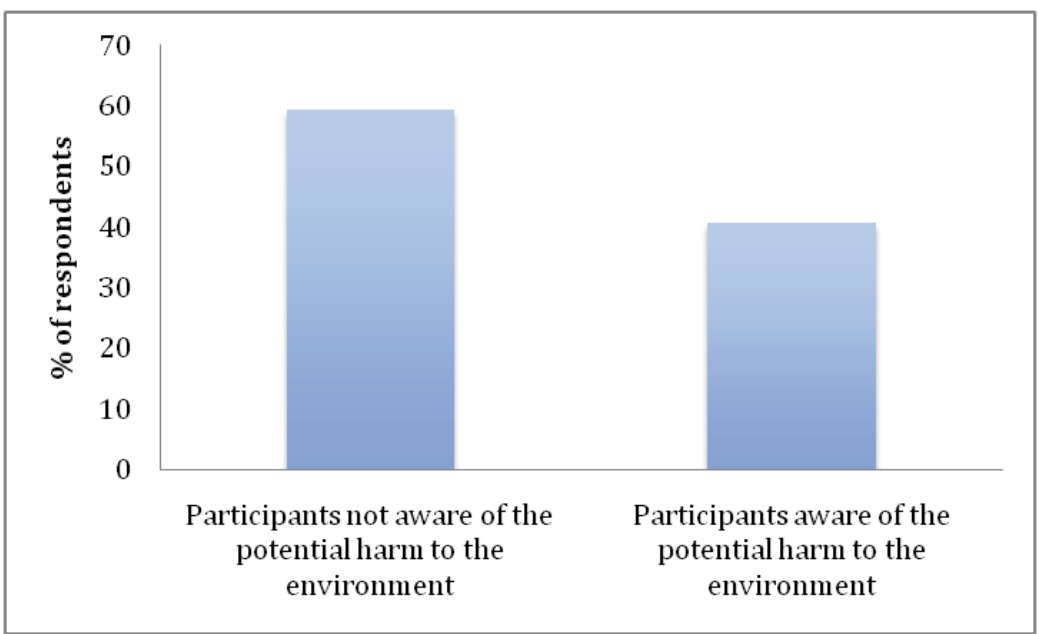

Figure 2: Awareness of the potential risk for the environment caused by improper medication disposal. 
The present study revealed that few cases $(4.1 \%)$ of accidental poisoning had been reported due to the presence of expired/ unused medication in the homes (Figure 3). Furthermore, the participant's response toward receiving instruction or guideline on proper disposal of expired medications was negative, $80.7 \%$ of them have not been advised by any health professionals, including physicians or pharmacists.
Additionally, expired medications that were kept in most of the homes have never been recorded nor collected by any agency prior this study. This finding has been supported by $92.4 \%$ of participants. Moreover, a significant number of participants (91\%) was more likely believed that returning expired/unused medications to a community pharmacy nearby their homes is a proper way for their disposal (Table 2).

Table 2: Participants approaches toward disposal of expired/unused medications $(n=145)$.

\begin{tabular}{lcc}
\hline Participants response & Number & $\%$ \\
\hline $\begin{array}{l}\text { Not receive advice from medical provider on proper disposal } \\
\text { of medication }\end{array}$ & 117 & 80.7 \\
$\begin{array}{l}\text { Expired medications have never been recorded nor collected } \\
\text { by any agency prior this study }\end{array}$ & 134 & 92.4 \\
$\begin{array}{l}\text { Suggest community pharmacy as a collection point for } \\
\text { expired medications for proper disposal of them }\end{array}$ & 132 & 91.0 \\
\hline
\end{tabular}

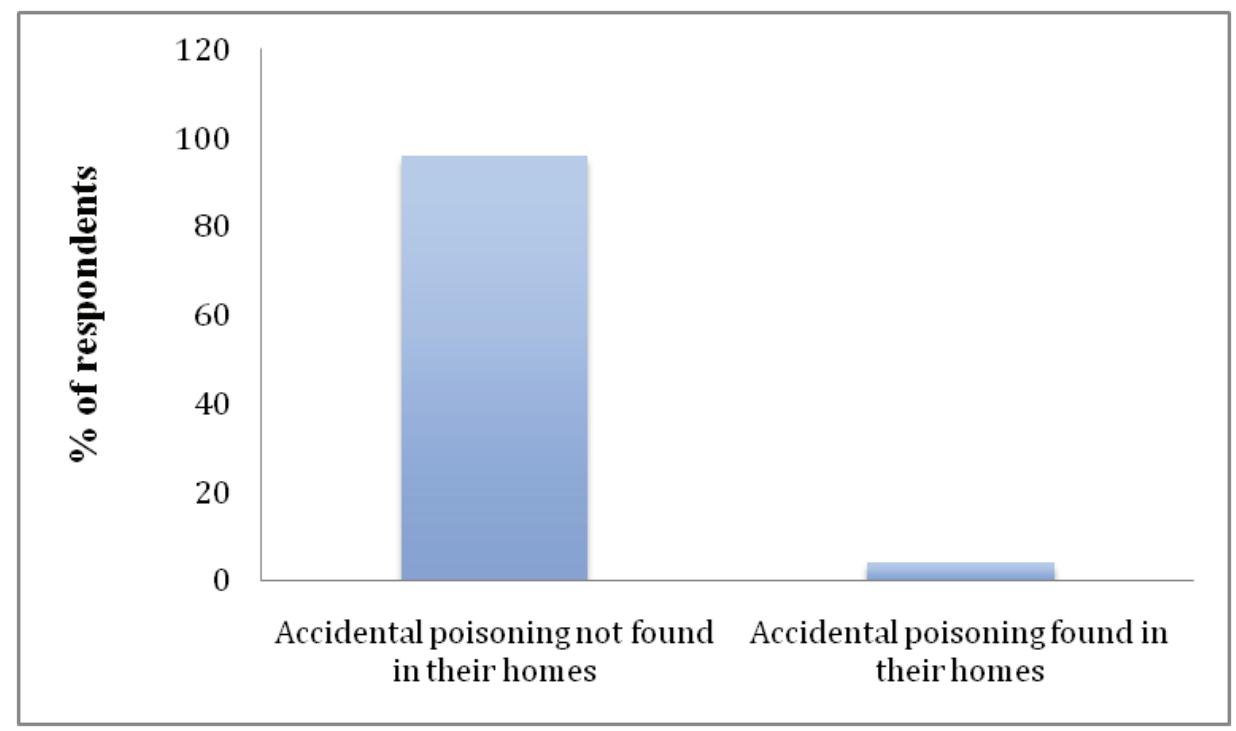

Figure 3: Reported accidental poisoning by expired/unused medications in homes. 
In the first part of this study, we aimed to quantitatively analyze the expired and unwanted medications in the surveyed houses. The results showed that out of 145 visited houses, these types of medications were found only in $37.9 \%$ of them, while the rest $(62.1 \%)$ threw away the unused medications in the garbage prior to the interview time. Quantitative analysis of the collected expired/unwanted medications from houses includes the number of items, dosage forms, their pharmacological categories and the total quantity of the solid dosage form and total units of the liquid dosage form (Tables 3 and 4).

Table 3: Quantity and number of items found in participant's home based on the dosage form.

\begin{tabular}{lccc}
\hline Dosage Form & Number of items & $\%$ & Quantity \\
\hline Tablets and Capsules & 90 & 72.6 & 4448 \\
Injectable & 6 & 4.83 & 39 \\
Syrup/Suspension & 6 & 4.83 & 40 \\
Topical Ointment/Cream & 15 & 12.1 & 79 \\
Others & 7 & 5.64 & 86 \\
\hline
\end{tabular}

Table 4: Quantity and categories of expired solid dosage form medicines found in the participant's homes in Sulaimani city (total quantity $=4448$ ).

\begin{tabular}{lccc}
\hline Drug Category & $\begin{array}{c}\text { Number of } \\
\text { items }\end{array}$ & Quantity & (\%) \\
\hline Antibiotics & 15 & 426 & 9.6 \\
Gastrointestinal & 11 & 648 & 14.6 \\
Analgesic and Non-Steroidal Anti-inflammatory & 8 & 633 & 14.2 \\
Tonics and Supplements & 13 & 734 & 16.5 \\
Antihistamines & 11 & 479 & 10.8 \\
Hormones & 7 & 486 & 10.9 \\
Bronchodilators & 2 & 88 & 1.97 \\
Antihypertensive and cardiovascular & 7 & 232 & 5.2 \\
Anticoagulant and antiplatelet & 3 & 186 & 4.18 \\
Antihyperlipidemic & 1 & 110 & 2.5 \\
Central nervous system & 5 & 161 & 3.6 \\
Miscellaneous & 7 & 265 & 5.95 \\
Total & 90 & 4448 & 100 \\
\hline
\end{tabular}


The total quantity of the solid dosage form collected from the surveyed houses was 4448 tablet or capsules; most of the collected drugs were tonics and supplements $(16.5 \%)$; then gastrointestinal drugs (14.6\%) and analgesics (14.2\%). In the second part of this study, the obtained results from the community pharmacies on disposal practice of expired /unused medications in workplace revealed that $38.7 \%$ of the community pharmacies throw away their expired medications in the garbage, while $46.8 \%$ return them to the suppliers (drug stores), and $1.6 \%$ destroy the expired medications in $\mathrm{DOH}$-incinerator
(Figure 4). Additionally, $58 \%$ of the community pharmacists involved in the current study encouraged a safe drug take-back program for the collection of expired/unused drugs, and they agreed to use their workplace as a collection point for expired/unused medications from houses nearby their pharmacy for proper disposal. On the other hand, $19.4 \%$ and $22.6 \%$ of the pharmacists recommended governmental hospital pharmacies and health centers respectively, for the collection of the expired medications from homes (Table 5).

Table 5: Community pharmacist's approaches toward Drug Take-Back Program for the collection of expired/unused medications $(n=62)$.

\begin{tabular}{lcc}
\hline Pharmacists approach & No. & (\%) \\
\hline $\begin{array}{l}\text { Pharmacists who agreed to use their pharmacy as a collection } \\
\text { point for expired medication from houses nearby their pharmacy } \\
\text { for proper disposal }\end{array}$ & 36 & 58.0 \\
$\begin{array}{l}\text { Pharmacists who recommended governmental hospital pharmacies } \\
\text { for collection of expired medication }\end{array}$ & 12 & 19.4 \\
$\begin{array}{l}\text { Pharmacists who recommended health center pharmacies for } \\
\text { collection of expired medication }\end{array}$ & 14 & 22.6 \\
Total & $\mathbf{6 2}$ & $\mathbf{1 0 0}$ \\
\hline
\end{tabular}

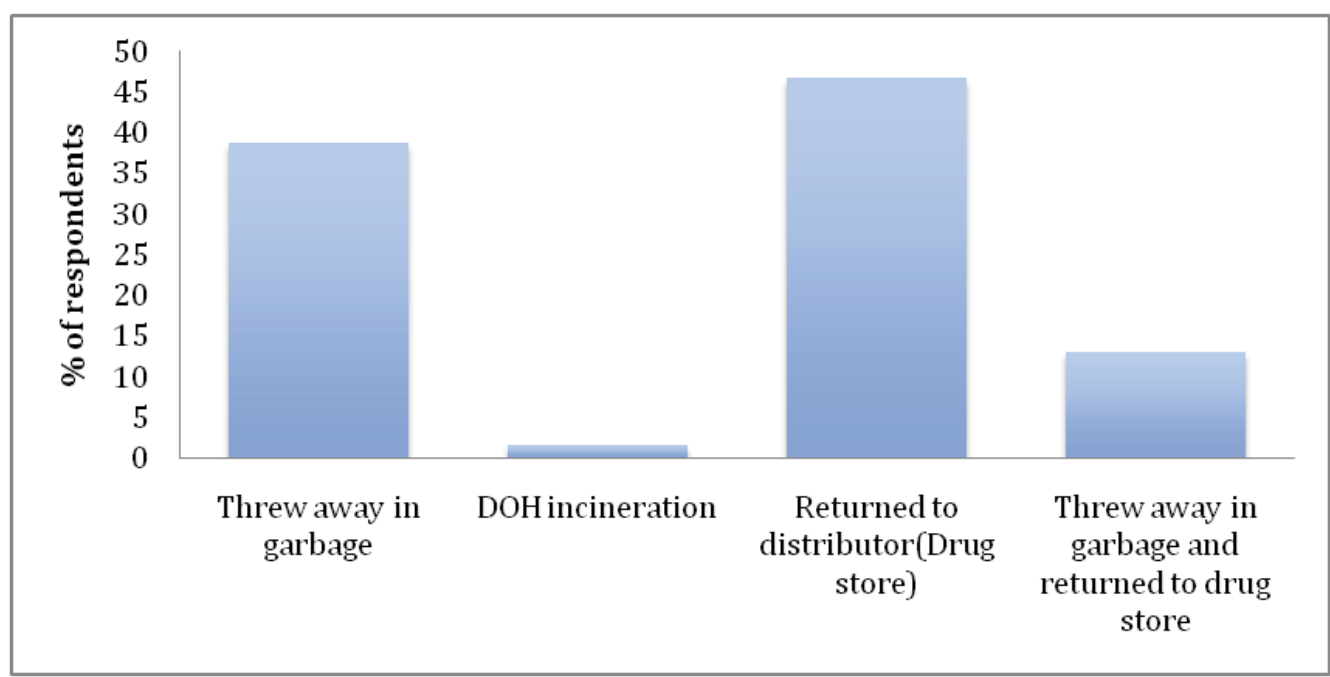

Figure 4: Disposal methods of expired/unused medications in community pharmacies in Sulaimani city. 


\section{Discussion}

Large quantities of unused or expired drugs have been documented in the community. This is common in developing countries, as self-medication is high and medicines are usually kept for re-use in the situation of a similar illness or to give it to someone else who might have a similar problem with them. ${ }^{16}$ This excess of residential pharmaceuticals leads to serious health and safety problems, significant opportunities for unintentional poisonings of children in the home, illegal distribution, substance misuse or abuse, and environmental contamination. ${ }^{17}$ Medication disposal habits are influenced by environmental awareness, availability of official state guidelines, dosage form, social and cultural attitudes. A huge pileup of expired and unused pharmaceuticals in the medicine cabinets among public reflects ignorance regarding disposal techniques and how drugs affect the environmental health. ${ }^{18}$ In the present study, massive quantities of expired and unwanted medications were collected from homes that were thrown away in unfriendly environmental methods of disposal. The most frequently collected expired and unused medications from the houses enrolled in the current study were tonics and supplements, gastrointestinal, analgesic and non-steroidal antiinflammatory drugs, hormones and antihistamines; the common approach followed for disposal of those medications at houses was throwing them away in the garbage (95.2\%). Although such disposal practice is unsafe for people's health as well as for the environment, many countries follow this method to get rid of unwanted medications. ${ }^{3,19}$ The present study conducted in Sulaimani, a city in Iraqi Kurdistan where the environmental monitoring and protection is not fully evaluated. The conformal guideline for disposal of expired medications and medical wastes exist only in governmental healthcare settings, including hospitals and healthcare centers, issued by Ministry of
Health $(\mathrm{MOH})$. However, this $\mathrm{MOH}$ guideline has neither specific rules for receiving and disposal of expired and unwanted medication of the public nor does the region have any take-back program that accepts unwanted medications from the public as many countries do. Based on the municipality procedures of disposal in Sulaimani and the area surrounding the city, the garbage is sent to Tanjaro area, south of the city in which there is no appropriate method for disposal of such wastes. The active ingredients in the disposed pharmaceuticals may find their way to the underground water and ecosystem. ${ }^{20}$ Although the present study did not determine the concentration of the active ingredients in the ecosystem, the finding of other studies indicates that their concentrations are negligible. However, long-term exposure to even low levels of multiple medications could be hazardous. Several types of drugs including antibiotics, anticonvulsants, mood stabilizers and sex hormones have been found in the drinking water consumed by millions of people, ${ }^{21}$ and traces of pharmaceuticals have been detected in soil, ground water, surface water, and drinking water. ${ }^{15,22}$ The presence of an official guideline for proper disposal of expired and unwanted medications has a major influence on how people in public dispose of their pharmaceutical wastes. $^{23}$ The present study focused on another aspect of ecopharmacovigilance, which is awareness of public regarding the impact of improper disposal of the expired or unwanted pharmaceutics on the environment, A significant number of housekeepers were unaware about the potential risks of improper disposal of expired medication on environment, as most of them (80.7\%) had not received any advice from health care professionals including physicians, pharmacists and nurses regarding the proper way of disposal. The obtained result is consistent with the study done by Aditya $^{24}$ on safe medication disposal, 
which states that $92 \%$ of respondents had never received any advice on drug disposal. Meanwhile, other studies ${ }^{25,26}$ showed that only $20 \%$ to $30 \%$ participants had received previous advice on safe medication disposal by a health care provider, and there is a role for patient education about proper disposal of unused and expired medications. We suggest that community pharmacies could play a vital role to decrease the environmental impact of disposing expired medication, both in public and community pharmacies, by assigning the community pharmacy as a collection point for the unused medication belong to the public. A significant number of the participants does agree with the idea that community pharmacy could be the best place for collecting expired medications for proper disposal. The obtained results were parallel with the study carried out in Kuwait, ${ }^{27}$ which states that $54.0 \%$ of participants thought that a system of taking medicines to pharmacies for safe disposal would be favorable. Many approaches to medication disposal are implemented in many countries, which play significant roles in reducing delivery of pharmaceuticals to the environment. Additionally, many forms of drug collection systems on the national, state, or local levels were implemented in about 30 countries, and the methods used for the collection of expired and unwanted medications vary among them. However, community pharmacies play a central role in the collection of these unwanted medications. ${ }^{6}$ In Iraq and particularly in Sulaimani city, basic education on appropriate disposal of unused medicines is lacking. Expired and unused medications are not returned to pharmacies for appropriate disposal similar to that followed in other developed countries. ${ }^{28}$ The current observation on disposal of expired or recalled medications in the community pharmacies also clarifies that there is no conformal guideline or method that pharmacist should follow in the disposal of pharmaceutical wastes and expired medications. More than half of the community pharmacists enrolled in the study encouraged the idea of returning unused medication to community pharmacies. They agreed to consider their workplaces as a collection point for expired medications as a way of proper disposal, although some of them recommend governmental setting such as hospital and healthcare center pharmacies as a better place for the collection of expired medication of public. The practice of sending waste medications in many countries, such as Sweden, to phar-macies for the destruction of active ingredients utilizing high-temperature incineration is common. ${ }^{29}$ This disposal and destruction system is state-controlled in conjunction with the nationwide pharmaceutical wholesaler and overseen by the Swedish Phar-maceutical Society. On the other hand, not all United State pharmacies accept returned medications, particularly controlled drugs. ${ }^{6}$ Similar attitudes and practices in pharmacies are common worldwide that increase the pharmaceuticals entering the environment in addition to that arising from direct household disposal. ${ }^{23}$ The present study did not perform qualitative detection of pharmaceuticals in the environment, which was necessary to confirm the detrimental effect of pharmaceutical wastes to the ecosystem.

\section{Conclusion}

In Sulaimani city, high amount of expired/ unused medications were kept in the households that necessitate establishing a procedure for disposal that ensures safety to human and environment. There is good interest in the collection of unused medications for proper disposal in the community pharmacies. Moreover, there is an urgent need for adopting a guideline by the healthcare authority to support the present findings.

\section{Conflicts of interest}

The author reports no conflicts of interest. 


\section{References}

1. Gray-Winnett MD, Davis CS, Yokley SG, Franks AS. From dispensing to disposal: the role of student pharmacists in medication disposal and the implementation of a take-back program. J Am Pharm Asso 2010; 50(5):613-8.

2. Smolen A. Role of the pharmacist in proper medication disposal. US Pharm 2011; 36:52-5.

3. El-Hamamsy M. Unused medications: How cost and how disposal of in Cairo, Egypt. IJPSR 2011; 2:21-7.

4. Kuspis A, Krenzelok P. What happens to expired medications? A survey of community medicine disposal. Vet Hum Toxicol 1996; 38:48-9.

5. Atinafu T, Takele A, Kassie A, Yehualaw A, Tesfaw G, Desseno $T$, et al. Unused medications disposal practice: The case of patients visiting university of gondar specialized teaching hospital, Gondar, Ethiopia. IJPSR 2014; 5:999-1005.

6. Glassmeyer ST, Hinchey EK, Boehme SE, Daughton CG, Ruhoy IS, Conerly $\mathrm{O}$, et al. Disposal practices for unwanted residential medications in the United States. Environ Int 2009; 35(3):566-72.

7. Daughton CG, Ruhoy IS. The afterlife of drugs and the role of pharmecovigilance. Drug Saf 2008; 31:1069-82.

8. Woodhouse B. Pharmaceuticals and other waste water products in our waters: a new can of worms? Southwest Hydrology 2003; 30: 12-3.

9. Stackelberg PE, Furlong ET, Meyer MT, Zaugg SD, Henderson AK, Reissman DB.Persistence of pharmaceutical compounds and other organic wastewater contaminants in a conventional drinking water treatment plant. Sci Total Environ 2004; 329:99-113.

10. Kumar R, Somrongthong R, Shaikh BT. Effectiveness of intensive healthcare waste management training model among health professionals at teaching hospitals of Pakistan: a quasi-experimental study. BMC Health Serv Res 2015; 15:81.

11. Jarvis $C L$, Seed $S M$, Silva $M$, Sullivan $K M$. Educational campaign for proper medication disposal. J Am Pharm Assoc 2009; 49:65-8.

12. Prakash V, Green RE, Pain DJ, Ranade SP, Saravanan S, Prakash N, et al. Recent changes in populations of resident Gyps vultures in India. J Bombay Nat Hist Soc 2007; 104:129-35.

13. Velo G, Moretti U. Ecopharmacovigilance for better health. Drug Saf 2010; 33(11):963-8.

14. Charles PG, Grayson ML. The dearth of new antibiotic development: Why we should be worried and what we can do about it. Med J Aust 2004; 181:549-53.

15. Tong AY, Peake BM, Braund R. Disposal practices for unused medications in New Zealand community pharmacies. J Prim Health Care 2011; 3(3):197-203.
16. Auta A, Omale S, Shalkur D, Abiodun AH. Unused medicines in Nigerian households: Types and disposal practices. J Pharmacol Pharmacother 2011; 2:195-6.

17. Law AV, Sakharkar $P$, Zargarzadeh A, Tai BW, Hess K, Hata M, et al. Taking stock of medication wastage: Unused medications in US households. Res Social Adm Pharm 2015; 11(4):571-8

18. Ruhoy IS, Daughton CG. Beyond the medicine cabinet: An analysis of where and why medications accumulate. Environ Int 2008; 34:1157-69.

19. Abahussain EA, Waheedi M, Koshy S. Practice, awareness and opinion of pharmacists toward disposal of unwanted medications in Kuwait. Saudi Pharm J 2012; 20(3):195-201.

20. Joss A, Zabczynski S, Gobel A, Hoffmann B, Loffler D, McArdell CS, et al. Biological degradation of pharmaceuticals in municipal wastewater treatment: Proposing a classification scheme. Water Res 2006; 40:1686-96.

21. McKie MJ, Andrews SA, Andrews RC. Conventional drinking water treatment and direct biofiltration for the removal of pharmaceuticals and artificial sweeteners: A pilot-scale approach. Sci Total Environ 2015; 544:10-17.

22. Coma A, Modamio P, Lastra CF, Bouvy ML, Marino EL. Returned medicines in community pharmacies of Barcelona, Spain. Pharm World Sci 2008; 30:272-7.

23. Tong AYC, Peake BM, Braund R. Disposal practices for unused medications around the world. Environ Int 2011; 7(1):292-8.

24. Aditya S. Safe medication disposal: Need to sensitize undergraduate students. Int J Pharm Life Sci 2013; 4:2475-80.

25. Seeheusen DA, Edwards J. Patient practices and beliefs concerning disposal of medications. J Am Board Fam Med 2006; 19:542-7.

26. Auta A, Banwat SB, Sarien CN, Nasara B, Atuluku MO. Medicines in pharmacy students' residence and self-medication practices. J Young Pharm 2012; 4:119-23.

27. Abahussain EA, Ball DE, Matowe WC Practice and opinion towards disposal of unused medication in Kuwait. Med Princ Pract 2006; 15(5):352-7.

28. Ali SE, Ibrahim MI, Palaian S. Medication storage and self-medication behavior among female students in Malaysia. Pharm Pract 2010; 8:226-32.

29. Persson M, Sabelstrom E, Gunnarsson B. Handling of unused prescription drugs, knowledge, behavior and attitude among Swedish people. Environ Int 2009; 35(5):771-4. 